\title{
Variations in CCL3L gene cluster sequence and non-specific gene copy numbers
}

\author{
Sadeep Shrestha ${ }^{1 *}$, Mawuli Nyaku', Jeffrey C Edberg ${ }^{2}$
}

\begin{abstract}
Background: Copy number variations (CNVS) of the gene CC chemokine ligand 3-like1 (CCL3L1) have been implicated in HIV-1 susceptibility, but the association has been inconsistent. CCL3L1 shares homology with a cluster of genes localized to chromosome 17q12, namely CCL3, CCL3L2, and, CCL3L3. These genes are involved in host defense and inflammatory processes. Several CNV assays have been developed for the CCL3L1 gene.

Findings: Through pairwise and multiple alignments of these genes, we have shown that the homology between these genes ranges from 50\% to $99 \%$ in complete gene sequences and from $70-100 \%$ in the exonic regions, with $C C L 3 L 1$ and CCL3L3 being identical. By use of MEGA 4 and BioEdit, we aligned sense primers, anti-sense primers, and probes used in several previously described assays against pre-multiple alignments of all four chemokine genes. Each set of probes and primers aligned and matched with overlapping sequences in at least two of the four genes, indicating that previously utilized RT-PCR based CNV assays are not specific for only CCL3L1. The four available assays measured median copies of 2 and 3-4 in European and African American, respectively. The concordance between the assays ranged from 0.44-0.83 suggesting individual discordant calls and inconsistencies with the assays from the expected gene coverage from the known sequence.
\end{abstract}

Conclusions: This indicates that some of the inconsistencies in the association studies could be due to assays that provide heterogenous results. Sequence information to determine CNV of the three genes separately would allow to test whether their association with the pathogenesis of a human disease or phenotype is affected by an individual gene or by a combination of these genes.

\section{Background}

A cluster of chemokines including the $C C L 3 L$-related gene family have been localized on chromosome 17q12 [1]. By sequencing a BAC clone located in this segmental duplication region, Modi identified 2 complete copies (CCL3L1 and CCL3L3) and one truncated copy (CCL3L2) of the CCL3 gene family [2]. It has been reported that individuals with more copies of CCL3L1 than their population median are less susceptible to HIV infection $[3,4]$. There seems to be a relationship between the copy number of CCL3L1-containing segmental duplications and viral load and HIV-specific CD4+ and CD8+ T cell responses [5]. The copy number of CCL3L1 influences risk of systemic lupus erythematosis (SLE) and modifies the SLE-influencing effects

\footnotetext{
* Correspondence: sshresth@uab.edu

'Department of Epidemiology, University of Alabama at Birmingham, School of Public Health, 1665 University Blvd, RPHB Room 217L, Birmingham, Alabama 35294-0022, USA
}

associated with the CCR5 genotype [6]; a higher copy number (>2) of CCL3L1 is a risk factor for rheumatoid arthritis [7]. There is CCR5-CCL3L1 gene-gene interaction in susceptibility to Kawasaki disease [8], and higher numbers of infant CCL3L1 gene copies are associated with reduced HIV transmission $[9,10]$. In theory, the higher the copy number, the higher the ligand concentration, which should protect from HIV infection or disease progression. Chimpanzees, with higher copies (median of nine copy numbers), do not develop AIDS; this suggests biological significance. Copy number variation $(\mathrm{CNV})$ of $C C L 3 L$ - genes also affects the rate of progression to AIDS in rhesus macaques [11]. Other studies, however, do not show an association [12,13]. Although differences may exist in HIV progression outcomes, treatment variations, or interactions with the coreceptor CCR5 that result in differential associations, the methods used to determine CNVs have not been compared. 
To avoid labor-intensive Southern blotting, the requirement for relatively large amounts of high-quality genomic DNA, and the inherent inaccuracies and high costs of other quantification techniques, high-throughput, real-time quantitative PCR (RT-PCR) assays have been developed to determine copy numbers. These procedures are applicable for CCL3L1. Since this gene cluster region is complex, some of the variations in the findings relevant to associations could be due to the different primers and probes used for the RT-PCR assays. To determine if this is the case, we evaluated different assays used to measure gene copy numbers of CCL3L1.

\section{Methods}

We searched PubMed with the terms "MIP- $1 \alpha \mathrm{P}$ or MIP-1alpha P or LD78 $\beta$ or LD78beta or CCL3L1" for articles published in English up to the end of Jan 2010, and screened for publications specific to HIV/AIDS (and also separately for other diseases) and involving use of RT-PCR-based assays for examining copy numbers of CCL3L1 gene. Sequences of primers and probes used in RT-PCR assays in these publications were subjected to a nucleotide blast search against the human genomic plus transcript database on the National Center for Biotechnology Information (NCBI) website http://blast.ncbi.nlm. nih.gov/Blast.cgi. The sequences of genes containing these blast results were obtained from the UCSC Genomic Browser and aligned to the human reference sequence. Locations of exons, introns and untranslated regions of these genes were annotated from the NCBI Genome Browser. Pairwise, and multiple alignments were performed on these gene sequences via ClustalW in Molecular Evolutionary Genetics Analysis (MEGA 4) [14] and in BioEdit [15]. Primers and probes were aligned individually with each gene and then with all pre-aligned genes in MEGA 4 and BioEdit.

We used four different assays from the current literature (CCL3L_PP1, CCL3L_PP2, CCL3L_PP3, and CCL3L_PP4 in Table 1) in a previously described subset of 47 European American and 48 African American healthy controls [16] to quantify and examine the distribution of the copy numbers and the concordance rates between different assays in the two populations were assessed. Briefly, we used the specific primer/probe combinations (as shown in Table 1) to quantify the copy numbers of CCL3L1 with the single-copy gene hemoglobin, beta $(H B B)$ serving as the internal control. Real-time PCR was performed using an AB 7500 Fast System (Applied Biosystems Inc.). Cycling conditions were: $2 \mathrm{~min}$ at $50^{\circ} \mathrm{C}, 10 \mathrm{~min}$ at $95^{\circ} \mathrm{C}$, and 40 cycles of $15 \mathrm{~s}$ at $92^{\circ} \mathrm{C}$ and $1 \mathrm{~min}$ at $60^{\circ} \mathrm{C}$. Test genomic DNA samples was diluted to obtain a concentration of $2.5 \mathrm{ng} /$ $\mu \mathrm{l}$, and $2 \mathrm{ul}$ (5 ng genomic DNA) was used in each reaction. We ran each sample in triplicates across three 96- well plates. We used the Applied Biosystems relative quantification program to determine gene copy numbers for the individual samples. The $H B B$ gene that is present at two copies per diploid genome was used to standardize the gene copy number counts. Consistent with previous studies, we performed RT-PCR for each individual in triplicate and determined the normalized relative copy number by generating a standard curve and then normalizing across samples by the results of the HBB control gene and dividing the value obtained by the reference individual. Rounding off the outcome from the previous step to the nearest integer provided the estimated copy number counts. The copy numbers matching in triplicates and/or duplicates was used as the final copy number for an individual sample.

\section{Results}

For the CCL3L1 gene, a Pubmed search generated 1059 articles, of which 218 were related to HIV/AIDS. Fifteen of the 218 articles were studies relating to CCL3L1 copy numbers; all involved RT-PCR-based assays. Primers and probes used for the studies are summarized in Table 1. Most of these RT-PCR assays were based on the assay described by Towson et al. [17]; a few had modifications. Four studies assessed association of CCL3L1 copy numbers with other diseases (Kawasaki disease, SLE, hepatitis C, and rheumatoid arthritis). All of these association studies used RT-PCR assays that were based on the CCL3L_PP1 primer-probe (described in Table 1). Two studies involved use of RT-PCR-based assays to examine mRNA expression of CCL3L1.

Query coverage of above $70 \%$ with $100 \%$ maximum identity from the nucleotide blast identified 4 genes, namely CCL3 (geneID: 6348), CCL3L1 (geneID: 6349), CCL3L2 (geneID: 390788), CCL3L3 (geneID: 414062), CCL18 (geneID: 6362) and CCL24 (geneID: 6369). The reference genomic sequences for CCL3 - (34415602 34417506), CCL3L1 - (34623842 - 34625730), CCL3L2 (34610211 - 34611454), CCL3L3 - (34522262 34524142) were mapped to human chromosome 17 sequence, accession \# NC_000017.10 (Figure 1). Of note, CCL18 (34391643 - 34398841) in chromosome 17 and CCL24 (75441114 - 75443033) also showed high homology (> 50\%) sequence. The annotations of exons, introns and untranslated regions of these genes are shown in Figure 1 (see additional file 1 for details). Since CCL3L2 is considered a pseudo-gene, locations of these regions were estimated based on the homology this gene shares with CCL3, CCL3L1 and CCL3L3. As shown in Table 2, the homology in the complete gene region of the four CCL3L related genes in chromosome $17 q 12$ was high (55.3 - 98.7\%) and even higher in the exonic region (71.9-100\%), with identical exonic sequences between CCL3L1 and CCL3L3. 
Table 1 Specificity of primer and probes sets used in different HIV/AIDS and other disease association studies of CCL3L-related CNVs and mRNA expression.

\begin{tabular}{|c|c|c|c|c|}
\hline \multirow[t]{2}{*}{$\#$} & \multirow{2}{*}{$\begin{array}{l}\text { Primer/Probe Sequences } \\
5^{\prime}-3^{\prime} \text { Sequence* }\end{array}$} & \multicolumn{2}{|c|}{ References } & \multirow[t]{2}{*}{ Specificity } \\
\hline & & HIV/AIDS & Other diseases & \\
\hline \multirow[t]{8}{*}{ CCL3L_PP1 } & F: TCTCCACAGCTTCCTAACCAAGA & {$[3,4]$,} & {$[6]^{a}$} & CCL3L1 \\
\hline & R: CTGGACCCACTCCTCACTGG & {$[5,9]$,} & {$[7]^{\mathrm{b}}$} & $C C L 3 \angle 3$ \\
\hline & P: AGGCCGGCAGGTCTGTGCTGA & {$[10,17]$} & {$[8]^{c}$} & \\
\hline & & {$[22,23]$,} & {$[21]^{d}$} & \\
\hline & & {$[24,25]$} & {$[32]^{e}$} & \\
\hline & & {$[26,27]$,} & & \\
\hline & & {$[28,29]$,} & & \\
\hline & & {$[30,31]$} & & \\
\hline \multirow[t]{3}{*}{ CCL3L_PP2 } & F: TTCTGGACCCACTCCTCACT & {$[12]$} & & CCL3L1 \\
\hline & R: CTTCTCCACAGCTTCCTAACCA & & & CCL3L3 \\
\hline & P: FAM-CTGCCGGCCTCTCT & & & \\
\hline \multirow[t]{3}{*}{ CCL3L_PP3 } & F: TGCCTATCTCCGTCTAGAGAGCTT & [13] & & CCL3L1 \\
\hline & R: AGAAGGAGGCAGCAGGACACT & [33] & & $C C L 3 L 2$ \\
\hline & P: FAM-TGACTCCAGGCAAGGG-MGB & & & CCL3L3 \\
\hline \multirow[t]{3}{*}{ CCL3L_PP4 } & F: GGGTATGACTTCTTGAACCGACAAA & [1] & & $C C L 3 L 1$ \\
\hline & R: GGTTCTCTGTTTCTCTATGTGATCCA & & & CCL3L3 \\
\hline & P: 6FAM-CATGAAGAGAGCTAAGAGAAC-MGBNFQ & & & \\
\hline \multicolumn{5}{|c|}{ mRNA expression } \\
\hline \multirow[t]{2}{*}{ CCL3L_PP5 } & F: TCTGCAACCAGGTCCTCTCT & & {$[34]^{f}$} & CCL3L1 \\
\hline & R: TITCTGGACCCACTCCTCAC & & & CCL3L3 \\
\hline \multirow[t]{2}{*}{ CCL3L_PP6 } & F:AGCCCTGAACAAAGCATCTG & & {$[35]^{9}$} & CCL3L1 \\
\hline & R:TGAGAGTTCCCCCTGTCCCCT & & & CCL3L3 \\
\hline \multicolumn{5}{|l|}{ Non-Human } \\
\hline & F: CCAGTGCTTAACCTTCCTCC & & & \\
\hline \multirow[t]{2}{*}{ CCL3L_PP7 } & R: TCAGGCACTCAGCTCCAGGT & [11] & & \\
\hline & P: AGGCCGGCAGGTCTGTGCTGACC & & & \\
\hline
\end{tabular}

${ }^{*} \mathrm{~F}=$ forward primer, $\mathrm{R}=$ Reverse primer, $\mathrm{P}=$ probe ${ }^{\mathrm{a}} \mathrm{SLE} ;{ }^{\mathrm{b}}$ Rheumatoid arthritis; ${ }^{\mathrm{C}}$ Kawasaki disease; ${ }^{\mathrm{d}}$ type 1 diabetes mellitus; ${ }^{\mathrm{e}}$ hepatitis $\mathrm{C} ;{ }^{\mathrm{f}} \mathrm{Human}$ glioblastoma; ${ }^{9}$ Dendritic cells exposed to contact allergens and irritants

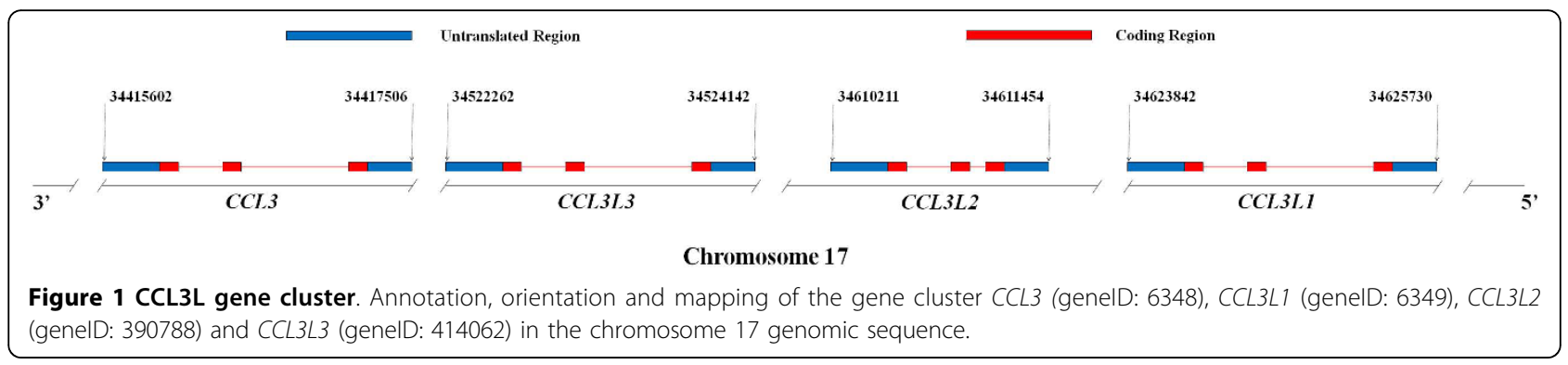

Table 2 Identity matrix (\%) between the CCL3L-related genes in complete (5'UTR, exons, introns and $3^{\prime}$ UTR) genomic sequence (bottom left) and b) exonic regions (top right)

\begin{tabular}{ccccc}
\hline & CCL3 & CCL3L1 & CCL3L2 & CCL3L3 \\
\hline$C C L 3$ & - & 0.957 & 0.713 & 0.957 \\
$C C L 3 L 1$ & 0.929 & - & 0.719 & 1.000 \\
$C C L 3 L 2$ & 0.525 & 0.553 & - & 0.719 \\
CCL3L3 & 0.921 & 0.987 & 0.560 & - \\
\hline
\end{tabular}

The primers and probes from the different studies (labeled CCL3L_PP1-CCL3L_PP7) for both RT-PCR and mRNA expression-based assays showed varying alignments with these four genes (additional file 1), suggesting non-specific amplifications and gene copy number determination. As shown in Table 1, all RT-PCR based assays were specific for both CCL3L1 and CCL3L3, except CCL3L_PP3, which was specific for CCL3L1, $C C L 3 L 2$, and CCL3L3 and CCL3L_PP7 for mRNA 


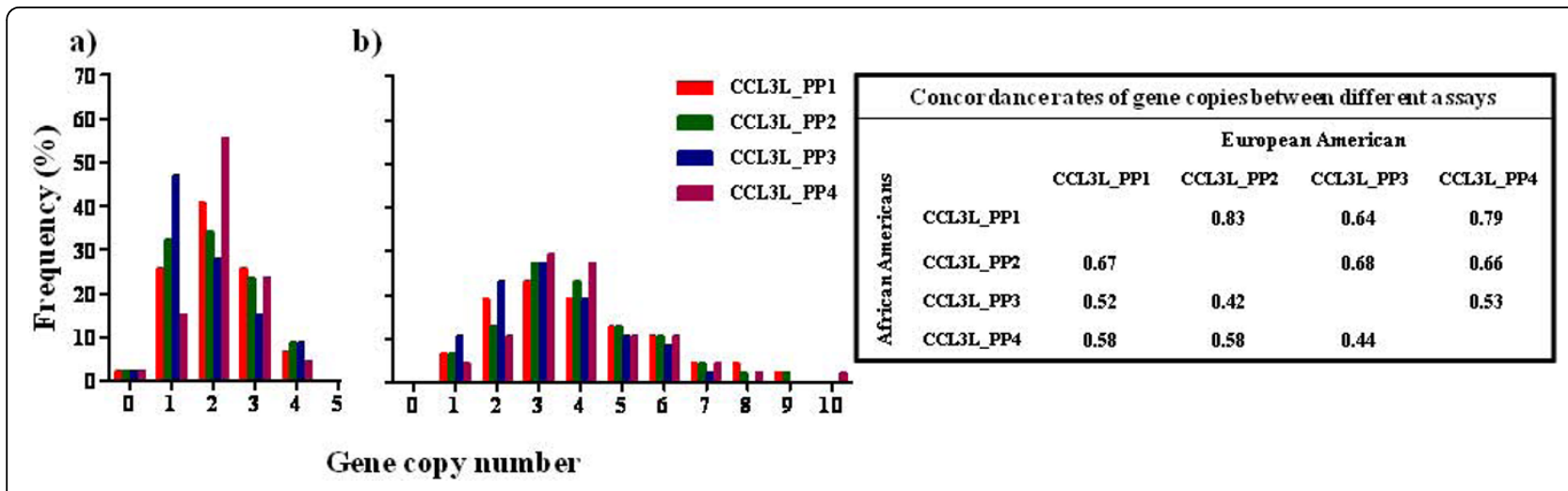

Figure 2 Gene copy number distribution in Caucasians and African-Americans. Distribution of CCL3L-related gene copy number by four RT-PCR assays: CCL3L_PP1, CCL3L_PP2, CCL3L_PP3, and CCL3L_PP4 in a) 47 Caucasians and b) 48 African-Americans. The concordance rates (same gene copy calls) between different assays are shown in the table.

expression. The primers/probes used in the study with macaques [11] aligned with the human genomic sequence as well but were nevertheless specific to both CCL3L1 and CCL3L3.

Figure 2 illustrates the distribution of CCL3L-related gene copy number based on the four different assays in a) Caucasians and b) African-Americans. Based on the sequence alignment (additional file 1), while CCL3_PP1, CCL3L_PP2, and CCL3L_PP4 are specific to CCL3L1 and CCL3L2, the assay CCL3_PP3 is specific to all three genes; CCL3L1, CCL3L2 and CCL3L3. The median gene copy was 2 for all assays in European Americans; 3 for CCL3L_PP3 and 4 for CCL3L_P1, CCL3L_P2, and CCL3L_P4 in African Americans and the means were 2.08, 2.04, 1.84 and 2.13 in European Americans and 3.93, 3.94, 3.3 and 4.04 in African Americans for CCL3_PP1, CCL3L_PP2, CCL3L_PP3 and CCL3L_PP4, respectively. Interestingly, CCL3L_PP1 had the lowest mean in both ethnic groups and CCL3L_PP4 had the highest mean and median in both ethnic groups. The concordance rates of gene copy calls were $83 \%, 64 \%$ and 79\% between CCL3L_PP1 and CCL3L1_PP2, CCL3L1_P3, and CCL3L1_P4 assays, respectively in European Americans and 67\%,52\%, and 58\%, respectively in African Americans; 68\% and 66\% between CCL3_PP2 and CCL3_PP3 and CCL3_PP4, respectively in European Americans and $42 \%$ and $58 \%$, respectively in African Americans and 53\% between CCL3_PP3 and CCL3_PP4 in European Americans and $44 \%$ in African Americans. Overall, the concordance rate seems to be relatively higher in European Americans than African Americans where the gene copy calls are higher with wider distributions.

\section{Discussion}

The non-specificity of different assays for CCL3L1 gene copy number raises the question of the gene specificity reported in earlier studies. Until the genetic architecture of this complex region is understood, it will be difficult to evaluate the genes individually and determine if there is an association between the copy numbers of all the genes in the cluster or if the association is specific to the copy number of only one gene [18]. Further, there might be situations in which a higher gene copy of one gene is detrimental and a higher gene copy of another is beneficial. Based on existing assays, the distribution of copy numbers of CCL3L1/CCL3L3 differs in different ethnic groups, (e.g., median copies of two, four, and six in Caucasians, Asians, and Africans, respectively) $[12,13]$. In our own results, while this seems to be the case at the population level, there seems to be inconsistencies between the different assays at the individual level, as shown specifically by the low concordance rates (Figure 2). Overall, CCL3L_PP4 has a higher mean than other assays both in African American and European American could possibly measure all three genes as previously described [1], but the sequence alignment shows that the assays are based specific to CCL3L1 and CCL3L3 and not to the truncated CCL3L2. Nevertheless, CCL3L_PP4 is not consistently larger across samples. On the contrary, CCL3L_PP4 which binds to all three genes has actually the lowest mean copy number. This clearly suggests non-specificity of the assays regardless of the sequence alignment.

If CCL3L1 and CCL3L3 are both diploid in nature then an individual should possess 4 copies of these genes based on the assays specific to two of these genes (Table 1: CCL3L_PP1, CCL3L_PP2, CCL3L_PP4, and CCL3L_PP5), so it is puzzling why there are several individuals with 1 or 2 copies, especially among Caucasians as shown in Figure 2. Do they lack one of these genes completely or do they have one copy of each or do they have different copy number of each gene? Any such discrepancy may confound the association from 
the biological function of the expressed proteins rather than the copies of the sequence in the genome. Thus, further investigation is needed to clarify the distribution for the sub-fractions of these genes and to understand how immunity with respect to the affect of each of these genes has evolved in different populations, including non-human primates, who tend to have higher copy numbers. Theoretically any assay performed to determine total CCL3L1 and CCL3L3 copies (although does not distinguish the dose of CCL3L1 and CCL3L3 in each individual) should reveal the same results and thus there should be no effect in the association. However, as we see from our results, the concordance rates are low. Without a gold-standard it is not possible to reliably assess which assay is better, but any misclassifications could lead to incorrect associations. Additionally, there are several other issues such as dye chemistry, reaction specificity/conditions and DNA concentrations that might also affect the assays [19]. Even with exact copy numbers, while there may not be differences at the sequence level, there may be differences at the expression levels and therefore may confound the overall association at the protein level rather than the nucleotide sequence level. For instance, the affinity of CCL3L1 is strongest for CCR5 and may be important to know how many copies of CCL3L1 an individual has versus how many of total CCL3L1 and CCL3L3. It remains to be shown how these two genes are differentially expressed and also how an expression of one gene might be affected by differential copy numbers of the others. They could enhance the affinity, reduce the affinity, or have no effect. However, while the expression and protein levels are important, the structural variants of these genes at the sequence level (copy numbers) needs to be understood and assayed properly to determine which ones are functional and what their levels are.

Since the extent of the non-specificity of the current RT-PCR based assays has not been well defined, the comparison to delineate the homologous regions provides basic information for assay development. The present data show that other genes, such as CCL18 and $C C L 24$, which may not be in the gene cluster, also have overlapping regions $(30-34 \%$ in CCL18 and $27-$ $44 \%$ in CCL24 with genes in CCL3L cluster). At present, different bio-informatics tools are needed to examine the sequences and to understand their complexities. While our inferences of the RT-PCR based assays are based on a single reference genome assembly, all previous assays were likely based on the reference sequence as well and thus our approach provides a less conservative specificity since polymorphisms between and within genes in a population could further confound the specificity of the primers/probes. For example, although the exonic sequences between CCL $3 L 1$ and CCL $3 L 3$ are identical, there is at least one SNP in the UTR and two in the introns of CCL3L1 and one in the intron of $C C L 3 L 3$ (additional file 1) that are uniquely polymorphic (based on the reference genome) and can be utilized to develop assays. However, it is yet to be determined if these are different within genes or between genes to make a more reliable assay. Additionally, variants between and within copies of the CCL3Lrelated genes might influence the function of these genes. For example, SNPs in CCL3 and CCL3L1 genes determine their production [20]. Thus, SNPs and copy numbers are important in examining the production and expression of these gene levels. Both should be assayed appropriately.

Recently, as an alternative to RT-PCR, a method for CCL3L1 copy number determination based on a paralogue ratio test (PRT) has been developed [21]. However, the primers are non-specific and align with both CCL3L1 and CCL3L3. With the current methodologies for determining gene copy numbers, a main assumption is that the derived gene copy number based on specific probes represents the whole gene. This may not always be the case, since only parts of the gene might be duplicated; this may be missed if the probe is not specific for this segment or may provide a false count when other segments of the gene are not amplified, especially the functional segments. In some cases, there might be a complete gene copy, but subtle differences may be present at the sequence level. The orientation of the gene might be opposite so that expression would not be the same, or there might be differences in single-nucleotide polymorphisms (SNPs) between copies. To account for these variables, complete sequence data of all copies could be required. In summary, we report homology at the nucleotide sequence level between the different $C C L 3 L$-related gene clusters and primers/probes for the RT-PCR based assays. The currently used assays for gene copies of CCL3L1 are evidently non-specific and thus could overestimate the copy numbers. Based on the overlapping and non-specific sequences between these genes, current gene copy assays, such as gene specific RT-PCR, pyrosequencing, paralogue ratio tests (PRT), multiplex amplifiable probe hybridization $(\mathrm{MAPH})$ or multiplex ligation-dependent probe amplification (MPLA), could be fine-tuned with broad-range nested PCR methods to avoid redundant sequences and other new assays developed. Special precautions, however, are needed to avoid the homologous sequences. Non-specificity of the laboratory methods for CNVs should not be overlooked as we develop different analytical methods to account for heterogeneity in association results. 
Additional file 1: Multiple primer-probe alignment with chemokine genes. Multiple alignments of the primer-probe pairs used for RT-PCR based assays in different studies with genomic sequences for four chemokine genes: CCL3, CCL3L1, CCL3L2 and CCL3L3. The sequences of the genes were obtained as follows: CCL3 - (34415602 - 34417506), CCL3L1 - (34623842 - 34625730), CCL3L2 - (34610211 - 34611454), and CCL3L3 - (34522262 - 34524142) from the genomic sequence of chromosome 17 sequence (Accession Number NC_000017.10). For each gene, untranslated region sequences are highlighted in blue, exons in red, and introns in green. Missing sequences are marked as "-"to optimize gene alignments. (Differences in the gene sequences are marked as follows: "**" $=$ CCL3L, "f" $=$ CCL3L1, " $\triangle "=C C L 3 L 2$, and " $+"=$ CCL3L3)

\section{Acknowledgements}

This work was supported in part by the Back of the Envelope Award from the UAB School of Public Health Dean's Office and the Component on Analytic and Epidemiologic Genetics of UAB's Heflin Center for Human Genetics (CAEG) Pilot Program Award. We would like to thank Dr. Robert Kimberly for providing the samples which were collected through the support of his grants P01-AR049084 and 5UL1 RR025777-02 from the NIH National Center for Research Resources.

\section{Author details}

'Department of Epidemiology, University of Alabama at Birmingham, School of Public Health, 1665 University Blvd, RPHB Room 217L, Birmingham, Alabama 35294-0022, USA. ${ }^{2}$ Division of Clinical Immunology and Rheumatology, University of Alabama at Birmingham, 1530 3rd Avenue South, Shelby 207, Birmingham, Alabama 35294-2182, USA.

\section{Authors' contributions}

SS conceived ideas to examine assays at the sequence level, re-examined the bioinformatics and drafted the manuscript. MN conducted the literature search, performed the bioinformatics and the laboratory assays. JCE assisted with the supervision of the assays, analysis and interpretation. All three authors read and approved the final manuscript.

\section{Competing interests}

The authors declare that they have no competing interests.

Received: 13 October 2009 Accepted: 16 March 2010

Published: 16 March 2010

\section{References}

1. Shostakovich-Koretskaya L, Catano G, Chykarenko ZA, He W, Gornalusse G, Mummidi S, Sanchez R, Dolan MJ, Ahuja SS, Clark RA, Kulkarni H, Ahuja SK Combinatorial content of CCL3L and CCL4L gene copy numbers influence HIV-AIDS susceptibility in Ukrainian children. AIDS 2009, 23(6):679-688.

2. Modi WS: CCL3L1 and CCL4L1 chemokine genes are located in a segmental duplication at chromosome 17q12. Genomics 2004, 83(4):735-738

3. Ahuja SK, Kulkarni H, Catano G, Agan BK, Camargo JF, He W, O'Connell RJ, Marconi VC, Delmar J, Eron J, Clark RA, Frost S, Martin J, Ahuja SS, Deeks SG, Little S, Richman D, Hecht FM, Dolan MJ: CCL3L1-CCR5 genotype influences durability of immune recovery during antiretroviral therapy of HIV-1-infected individuals. Nat Med 2008, 14(4):413-420.

4. Gonzalez E, Kulkarni H, Bolivar H, Mangano A, Sanchez R, Catano G, Nibbs RJ, Freedman Bl, Quinones MP, Bamshad MJ, Murthy KK, Rovin BH, Bradley W, Clark RA, Anderson SA, O'connell RJ, Agan BK, Ahuja SS, Bologna R, Sen L, Dolan MJ, Ahuja SK: The influence of CCL3L1 genecontaining segmental duplications on HIV-1/AIDS susceptibility. Science 2005, 307(5714):1434-1440

5. Shalekoff S, Meddows-Taylor S, Schramm DB, Donninger SL, Gray GE, Sherman GG, Coovadia AH, Kuhn L, Tiemessen CT: Host CCL3L1 gene copy number in relation to HIV-1-specific CD4+ and CD8+ T-cell responses and viral load in South African women. J Acquir Immune Defic Syndr 2008, 48(3):245-254.
6. Mamtani M, Rovin B, Brey R, Camargo JF, Kulkarni H, Herrera M, Correa P, Holliday S, Anaya JM, Ahuja SK: CCL3L1 gene-containing segmental duplications and polymorphisms in CCR5 affect risk of systemic lupus erythaematosus. Ann Rheum Dis 2008, 67(8):1076-1083.

7. McKinney C, Merriman ME, Chapman PT, Gow PJ, Harrison AA, Highton J, Jones PB, McLean L, O'Donnell JL, Pokorny V, Spellerberg M, Stamp LK, Willis J, Steer S, Merriman TR: Evidence for an influence of chemokine ligand 3-like 1 (CCL3L1) gene copy number on susceptibility to rheumatoid arthritis. Ann Rheum Dis 2008, 67(3):409-413.

8. Burns JC, Shimizu C, Gonzalez E, Kulkarni H, Patel S, Shike H, Sundel RS, Newburger JW, Ahuja SK: Genetic variations in the receptor-ligand pair CCR5 and CCL3L1 are important determinants of susceptibility to Kawasaki disease. J Infect Dis 2005, 192(2):344-349.

9. Kuhn L, Schramm DB, Donninger S, Meddows-Taylor S, Coovadia AH, Sherman GG, Gray GE, Tiemessen CT: African infants' CCL3 gene copies influence perinatal HIV transmission in the absence of maternal nevirapine. AIDS 2007, 21(13):1753-1761.

10. Meddows-Taylor S, Donninger SL, Paximadis M, Schramm DB, Anthony FS, Gray GE, Kuhn L, Tiemessen CT: Reduced ability of newborns to produce CCL3 is associated with increased susceptibility to perinatal human immunodeficiency virus 1 transmission. J Gen Virol 2006, 87(Pt 7):2055-2065.

11. Degenhardt JD, de Candia P, Chabot A, Schwartz S, Henderson L, Ling B, Hunter M, Jiang Z, Palermo RE, Katze M, Eichler EE, Ventura M, Rogers J, Marx P, Gilad Y, Bustamante CD: Copy number variation of CCL3-like genes affects rate of progression to simian-AIDS in Rhesus Macaques (Macaca mulatta). PLoS Genet 2009, 5(1):e1000346.

12. Shao W, Tang J, Song W, Wang C, Li Y, Wilson CM, Kaslow RA: CCL3L1 and CCL4L1: variable gene copy number in adolescents with and without human immunodeficiency virus type 1 (HIV-1) infection. Genes Immun 2007, 8(3):224-231.

13. Nakajima T, Kaur G, Mehra N, Kimura A: HIV-1/AIDS susceptibility and copy number variation in CCL3L1, a gene encoding a natural ligand for HIV-1 co-receptor CCR5. Cytogenet Genome Res 2008, 123(1-4):156-160.

14. Kumar S, Nei M, Dudley J, Tamura K: MEGA: a biologist-centric software for evolutionary analysis of DNA and protein sequences. Brief Bioinform 2008, 9(4):299-306.

15. Hall TA: BioEdit: A user-friendly biological sequence alignment editor and analysis program for Windows 95/98/NT. Nucleic Acids Symp Ser 1999, 41:95-98.

16. Edberg JC, Wu J, Langefeld CD, Brown EE, Marion MC, McGwin G Jr, Petri M, Ramsey-Goldman R, Reveille JD, Frank SG, Kaufman KM, Harley JB, Alarcón GS, Kimberly RP: Genetic variation in the CRP promoter: association with systemic lupus erythematosus. Hum Mol Genet 2008, 17(8):1147-1155.

17. Townson JR, Barcellos LF, Nibbs RJ: Gene copy number regulates the production of the human chemokine CCL3-L1. Eur J Immunol 2002, 32(10):3016-3026.

18. Shrestha S, Tang J, Kaslow RA: Gene copy number: learning to count past two. Nat Med 2009, 15(10):1127-1129.

19. He W, Kulkarni H, Castiblanco J, Shimizu C, Aluyen U, Maldonado R, Carrillo A, Griffin M, Lipsitt A, Beachy L, Shostakovich-Koretskaya L, Mangano A, Sen L, Nibbs RJ, Tiemessen CT, Bolivar H, Bamshad MJ, Clark RA, Burns JC, Dolan MJ, Ahuja SK: Reply to: "Experimental aspects of copy number variant assays at CCL3L1". Nat Med 2009, 15(10):1117-1120.

20. Paximadis M, Mohanlal N, Gray GE, Kuhn L, Tiemessen CT: Identification of new variants within the two functional genes CCL3 and CCL3L encoding the CCL3 (MIP-1alpha) chemokine: implications for HIV-1 infection. Int J Immunogenet 2009, 36(1):21-32.

21. Field SF, Howson JM, Maier LM, Walker S, Walker NM, Smyth DJ, Armour JA, Clayton DG, Todd JA: Experimental aspects of copy number variant assays at CCL3L1. Nat Med 2009, 15(10):1115-1117.

22. Thomas SM, Tse DB, Ketner DS, Rochford G, Meyer DA, Zade DD, Halkitis PN, Nadas A, Borkowsky W, Marmor M: CCR5 expression and duration of high risk sexual activity among HIV-seronegative men who have sex with men. AIDS 2006, 20(14):1879-1883.

23. Pilotti E, Elviri L, Vicenzi E, Bertazzoni U, Re MC, Allibardi S, Poli G, Casoli C: Postgenomic up-regulation of CCL3L1 expression in HTLV-2-infected persons curtails HIV-1 replication. Blood 2007, 109(5):1850-1856.

24. Ketas TJ, Kuhmann SE, Palmer A, Zurita J, He W, Ahuja SK, Klasse PJ, Moore JP: Cell surface expression of CCR5 and other host factors 
influence the inhibition of HIV-1 infection of human lymphocytes by CCR5 ligands. Virology 2007, 364(2):281-290.

25. Dolan MJ, Kulkarni H, Camargo JF, He W, Smith A, Anaya JM, Miura T, Hecht FM, Mamtani M, Pereyra F, Marconi V, Mangano A, Sen L, Bologna R, Clark RA, Anderson SA, Delmar J, O'Connell RJ, Lloyd A, Martin J, Ahuja SS, Agan BK, Walker BD, Deeks SG, Ahuja SK: CCL3L1 and CCR5 influence cellmediated immunity and affect HIV-AIDS pathogenesis via viral entryindependent mechanisms. Nat Immunol 2007, 8(12):1324-1336.

26. Kulkarni H, Agan BK, Marconi VC, O'Connell RJ, Camargo JF, He W, Delmar J, Phelps KR, Crawford G, Clark RA, Dolan MJ, Ahuja SK: CCL3L1-CCR5 genotype improves the assessment of AIDS Risk in HIV-1-infected individuals. PLOS ONE 2008, 3(9):e3165.

27. Kulkarni H, Marconi VC, Agan BK, MCArthur C, Crawford G, Clark RA, Dolan MJ, Ahuja SK: Role of CCL3L1-CCR5 genotypes in the epidemic spread of HIV-1 and evaluation of vaccine efficacy. PLOS ONE 2008, 3(11): e3671.

28. Huik K, Sadam M, Karki T, Avi R, Krispin T, Paap P, Ruutel K, Uuskula A, Talu A, Abel-Ollo K, Lutsar I: CCL3L1 Copy Number Is a Strong Genetic Determinant of HIV Seropositivity in Caucasian Intravenous Drug Users. $J$ Infect Dis 2010, 201(5):730-9.

29. Rathore A, Chatterjee A, Sivarama P, Yamamoto N, Singhal PK, Dhole TN: Association of CCR5-59029 A/G and CCL3L1 copy number polymorphism with HIV type 1 transmission/progression among HIV type 1-seropositive and repeatedly sexually exposed HIV type 1seronegative North Indians. AIDS Res Hum Retroviruses 2009, 25(11):1149-1156.

30. Bhattacharya T, Stanton J, Kim EY, Kunstman KJ, Phair JP, Jacobson LP, Wolinsky SM: Reply to: "CCL3L1 and HIV/AIDS susceptibility". Nat Med 2009, 15(10):1112-1115.

31. Urban TJ, Weintrob AC, Fellay J, Colombo S, Shianna KV, Gumbs C, Rotger M, Pelak K, Dang KK, Detels R, Martinson JJ, O'Brien SJ, Letvin NL, McMichael AJ, Haynes BF, Carrington M, Telenti A, Michael NL, Goldstein DB: CCL3L1 and HIV/AIDS susceptibility. Nat Med 2009, 15(10):1110-1112.

32. Grunhage F, Nattermann J, Gressner OA, Wasmuth HE, Hellerbrand C, Sauerbruch T, Spengler U, Lammert F: Lower copy numbers of the chemokine CCL3L1 gene in patients with chronic hepatitis C. J Hepatol 2010, 52(2):153-9.

33. Nakajima T, Ohtani H, Naruse T, Shibata H, Mimaya Jl, Terunuma H, Kimura A: Copy number variations of CCL3L1 and long-term prognosis of HIV-1 infection in asymptomatic HIV-infected Japanese with hemophilia. Immunogenetics 2007, 59(10):793-798.

34. Kouno J, Nagai H, Nagahata T, Onda M, Yamaguchi H, Adachi K, Takahashi H, Teramoto A, Emi M: Up-regulation of CC chemokine, CCL3L1, and receptors, CCR3, CCR5 in human glioblastoma that promotes cell growth. J Neurooncol 2004, 70(3):301-307.

35. Verheyen GR, Schoeters E, Nuijten JM, Heuvel Van Den RL, Nelissen I, Witters H, Van Tendeloo VF, Berneman ZN, Schoeters GE: Cytokine transcript profiling in CD34+-progenitor derived dendritic cells exposed to contact allergens and irritants. Toxicol Lett 2005, 155(1):187-194.

doi:10.1186/1756-0500-3-74

Cite this article as: Shrestha et al.: Variations in CCL3L gene cluster sequence and non-specific gene copy numbers. BMC Research Notes 2010 3:74.

\section{Submit your next manuscript to BioMed Central and take full advantage of:}

- Convenient online submission

- Thorough peer review

- No space constraints or color figure charges

- Immediate publication on acceptance

- Inclusion in PubMed, CAS, Scopus and Google Scholar

- Research which is freely available for redistribution 